\title{
SERUM AMYLOID A AS A NOVEL MARKER TO MORBIDLADHERENT PLACENTA
}

\author{
By

\begin{abstract}
Khaled Zakaria El-Sheikha, Abd El-Monsef Abd El-Hamed Sedek, Ahmed Abdul-Hameid Abo Zeid*and Amr Hassan Mohamed El-Shayeb
\end{abstract} \\ Department of Obstetrics \& Gynecology and Clinical Pathology*, Faculty of Medicine, \\ Al-Azhar University
}

*Corresponding Author: Amr Hassan Mohamed El Shayeb, Mobile: 01011443465

E-Mail: dramrelshayeb@gmail.com

\begin{abstract}
Background: Placenta accreta is a placenta where the placental villi adhere directly to the myometrium, placenta increta is a placenta where placental villi invade into the myometrium, and a placenta percreta is a placenta where the placental villi invade through the myometrium and into the serosa. About $75 \%$ of morbidly adherent placentas are placenta accretas, $18 \%$ are placenta incretas, and 7\% are placenta percretas.
\end{abstract}

Objective: To detect the changes of serum amyloid A in women with morbidly adherent placenta, to assess the changes of serum amyloid A in women with morbidly adherent placenta and to assess use serum amyloid A as biological marker beside ultrasound \& doppler findings for prenatal detection of morbidly adherent placenta.

Patients and Methods: This study was conducted on women attending Al Azhar University Maternity Hospital, Obstetric clinic or emergency room and admitted to antepartum inpatient high-risk service. The current study had been conducted on 60 pregnant women who were divided into three equal groups as follows: Group I: placenta previa. Group II: placenta accreta or increta and Group III (control group): included normal pregnant women.

Results: Regarding sensitivity and specificity of serum amyloid-A, maternal serum amyloid-A level $\geq 15.3$ $(\mu \mathrm{g} / \mathrm{mL})$ had high specificity\& PPV, and moderate sensitivity\& NPV in differentiating previa group. Also, level $\geq 15.3(\mu \mathrm{g} / \mathrm{mL})$ had high specificity\& PPV and low sensitivity\& NPV in differentiating accreta group from control group. In addition to that maternal serum amyloid-A level $\geq 15.3(\mu \mathrm{g} / \mathrm{mL})$ had high specificity\& PPV and low sensitivity\& NPV in differentiating previa/accreta groups.

Conclusion: Morbidly adherent placenta (MAP) was characterized by failure of the placenta to separate at delivery, with potential for significant perinatal and maternal morbidity and mortality. Detection of level of maternal SAA can be used as an additional tool to detect MAP.

Keywords: Serum Amyloid A, placenta.

\section{INTRODUCTION}

Morbidly adherent placenta (MAP), including placenta accreta, increta and percreta, is characterized by failure of the placenta to separate at delivery, with potential for significant perinatal and maternal morbidity and mortality.
Placenta accreta occurrence has risen steadily to 1 in 533 between the years 1982 and 2002. This 13-fold increase parallels the increase in cesarean delivery (CD). When prior $\mathrm{CD}$ is combined with placenta previa, the risk for accreta increases with each prior $\mathrm{CD}$, from 11 to $40 \%, 61$ and $67 \%$ for one, two, three and 
four prior CDs, respectively (Goh and Zalud, 2016).

While multiple risk factors for morbidly adherent placenta have been described mechanisms of accreta development remain opaque and predelivery prediction is limited. Proposed mechanisms of accreta include excessive trophoblast invasion into the myometrium (Valentini et al, 2017). Deficient decidua enabling placental implantation onto the myometrium, suggested by increased accreta risk with previa alone, and a combination of both (Bartels et al, 2018).

Antenatal diagnosis of placenta accreta, as it can reduce maternal morbidity by enabling for a scheduled delivery by a multidisciplinary team in a tertiary care center. Ultrasound identifies many, but not all, women with MAP and without significant benefit from magnetic resonance imaging (Cheung and Chan, 2012).

SAA exerts immune-regulatory effects and key effects on trophoblastic migration, invasion, and differentiation. At low concentrations, SAA regulates trophoblast invasion and metalloprotease activity within the placental microenvironment, both of which are important for placental homeostasis and placental invasion (Sandri et al., 2014).

Regarding Serum amyloid A (SAA), which is a family of apolipoproteins associated with high-density lipoprotein (HDL) in plasma. Different isoforms of SAA are expressed constitutively (constitutive SAAs) at different levels or in response to inflammatory stimuli (acute phase SAAs). These proteins are produced predominantly by the liver. The conservation of these proteins throughout invertebrates and vertebrates suggests that SAAs play a highly essential role in all animals. Acute-phase serum amyloid A proteins (A-SAAs) are secreted during the acute phase of inflammation. Regarding ultrasonography features of placental lacunae, it appears as multiple linear, irregular vascular spaces within the placenta has been found to be predictive of placenta accreta. It has been shown to have the highest sensitivity to detect placenta accreta among the other diagnostic features. In patients who had a previous caesarean delivery and a lowlying anterior placenta, the lower uterine segment has been measured, and it was found that all patients with placenta accreta had a myometrium of less than 1 $\mathrm{mm}$ This was shown to be as predictive for morbidly-adherent placenta as placental lacunae (Tikkanen et al., 2011).

The present worke aimed to detect the changes of serum amyloid $\mathrm{A}$ in women with morbidly adherent placenta and assess the changes of serum amyloid $\mathrm{A}$ in women with morbidly adherent placenta.

\section{PATIENTS AND METHODS}

Site: This study was conducted on women attending Al-Azhar University Maternity Hospital, Obstetric clinic or emergency room and admitted to antepartum inpatient high-risk service.

Study population: The current study had been conducted on (60) pregnant women who were divided into three groups as follows: Group I: including (20) women with placenta previa. Group II: including (20) women with placenta accreta or increta. Group III (control group): which included (20) normal pregnant women. 
Women were recruited according to the following inclusion and exclusion criteria.

\section{Inclusion criteria:}

Age: $\geq 18$ years old. Gestational age $\geq$ 28 weeks' gestation. Previous cesarean section or hysterotomy. The diagnosis is usually established by ultrasonography and occasionally supplemented by Doppler.

\section{Exclusion criteria:}

Patients with fetal and placental abnormalities (other than placenta 7 previa, accreta and increta). Ruptured fetal membranes. Clinical signs of infection. Multiple fetuses. Chronic hypertension. Renal disease. Diabetes mellitus.

\section{Ethical issues:}

The protocol of the study was presented for approval by the ethical committee of the Department of Gynecology and Obstetrics of Al-Zhar University Maternity Hospital.

\section{Consent process:}

The population sample under study was informed about research protocol and informed consents are granted from each participant before inclusion.

\section{Study design:}

Type of study: Prospective cohort observational study.

Methodology: A detailed history and thorough physical examination of all participants had been carried out. A complete laboratory investigation was done, i.e. A complete blood picture with platelet count. Liver functions test. Renal function test. Coagulation profile. Fasting two hours blood glucose level.
Intervention: Patients upon admission, after diagnosis of placenta previa, accreta or increta. A sample of venous blood had been taken from each patient participating in the study under aseptic conditions.

Laboratory method: Blood samples were centrifuged at $2500 \mathrm{~g}$ for 15 minutes at $4^{\circ} \mathrm{C}$, separated into serum aliquots, and stored at $-80^{\circ} \mathrm{C}$ until used for the SAA assay. Levels of SAA had been be assayed simultaneously for both groups using the same microliter plates provided with the Human SAA solid-phases and which enzyme-linked immune-sorbent assay kit (Bio Source Europe, Nivelles, Belgium), according to the manufacturer's protocol. The inter-assay and intra-assay coefficients of variation were $7.4 \%$ and $6.1 \%$, respectively. The sensitivity had been $<0.004 \mu \mathrm{g} / \mathrm{mL}$.

\section{Data collection:}

Demographic data, delivery outcomes and laboratory evaluations were recorded and compared in both groups. Data or results which are collected after arrangement in suitable manner by a process known as processing of data may be manualor computerized. These data should be confidentially protected.

\section{Statistical Analysis:}

Data were collected, revised, coded and entered to the Statistical Package for Social Science (IBM SPSS) version 23. The quantitative data were presented as mean, standard deviations and ranges when their distribution found parametric. The comparison between two independent groups with quantitative data and parametric distribution were done by using Independent t-test; while the comparison between more than two group 
was done by Using One Way ANOVA test

Spearman correlation coefficients were used to assess the correlation between two quantitative parameters in the same group.

Receiver operating characteristic curve (ROC) was used in the quantitative form to determine best cut of point, sensitivity, specificity, positive predictive value (PPV), negative predictive value (NPV) and AUC of serum Amyloid A.

The confidence interval was set to $95 \%$ and the margin of error accepted was set to $5 \%$. So, p-value was considered significant when $\mathrm{P}$-value $>0.05$.

\section{RESULTS}

There was a statistically significant difference found between two groups regarding number of $\mathrm{CS}$, while there was no statistically significant difference found between two groups regarding Age, BMI, and GA (Table 1).

Table (1): Comparison between normal \& placenta(previa +accrete) groups regarding demographic data

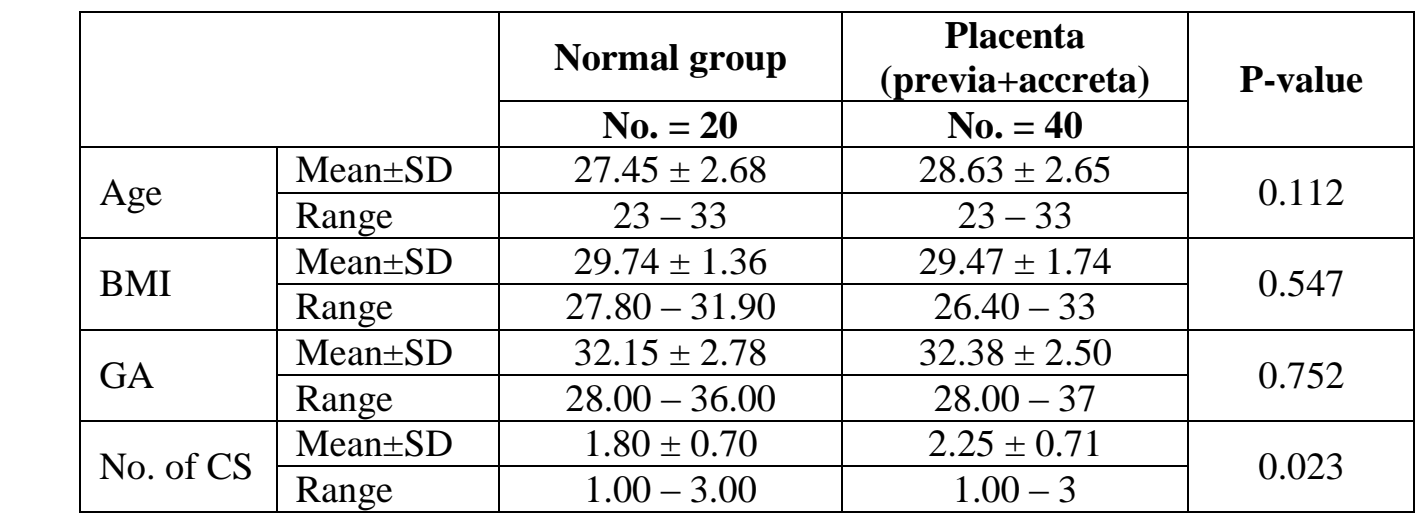

$\bullet:$ Independent t-test

There was a statistically significant difference between two groups regarding serum amyloid A level (Table 2).

Table (2): Serum amyloid $A$ in normal group and placenta (previa and accreta)

\begin{tabular}{|l|c|c|c|}
\hline \multirow{2}{*}{ Serum Amyloid A } & Normal group & Placenta (previa+ accreta) & \multirow{2}{*}{ P-value } \\
\cline { 2 - 3 } & No. $=\mathbf{2 0}$ & No. $=\mathbf{4 0}$ & \multirow{2}{*}{0.001} \\
\hline Mean \pm SD & $11.56 \pm 2.19$ & $19.86 \pm 5.72$ & \\
\hline Range & $8.80-16.20$ & $9.20-30.3$ & \\
\hline
\end{tabular}

$\bullet$ Independent t-test

There was a statistcitally significant difference between the three groups regarding age, while there was no statistical significance difference between them regarding BMI, GA, and number of cesarean section (Table 3). 


\section{SERUM AMYLOID A AS A NOVEL MARKER TO MORBIDLADHERENT... 441}

Table (3): Demographic data btween three groups (normal, placenta previa and placenta accreta)

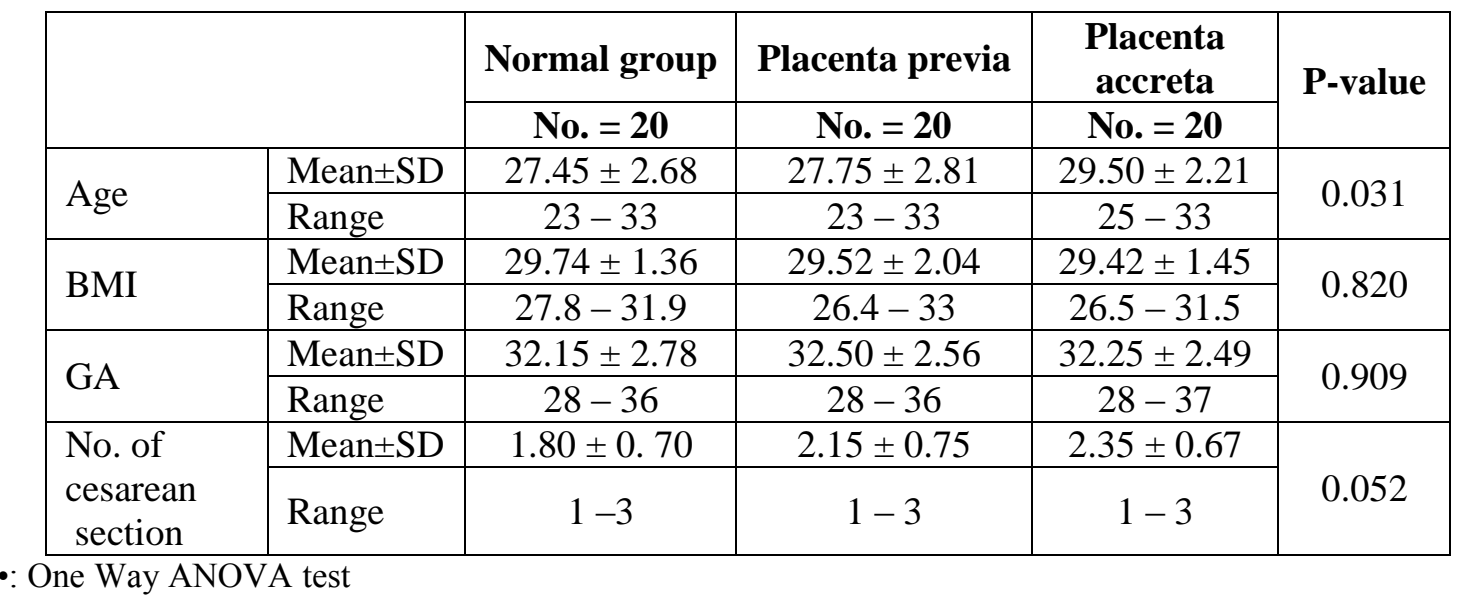

There was no statistically significant difference between normal group and placenta previa group, while placenta accreta group was found with higher age than normal and placenta previa group with p.value 0.015 and 0.036 respectively (Table 4).

Table (4): Post Hoc analysis by LSD

\begin{tabular}{|l|c|c|c|}
\hline \multirow{2}{*}{} & \multicolumn{3}{|c|}{ Post Hoc analysis by LSD } \\
\cline { 2 - 4 } & P1 & P2 & P3 \\
\hline Age & $\mathbf{0 . 7 1 5}$ & $\mathbf{0 . 0 1 5}$ & $\mathbf{0 . 0 3 6}$ \\
\hline
\end{tabular}

P1: Normal Vs Previa no significance

P2: Normal Vs Accreta significant

P3: Previa Vs Accreta significant

The best cut off point regarding serum amyloid A to differentiate between normal placenta patients and placenta accreta and previa patients was found > 15.4 with sensitivity of $77.5 \%$, specificity of $95 \%$ and area under curve (AUC) of $90.7 \%$ (Figure 1).

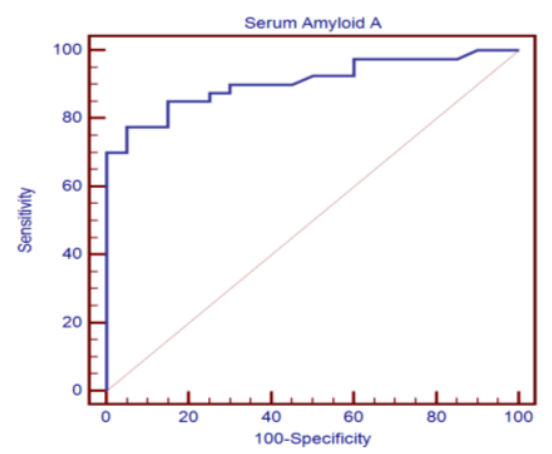

\begin{tabular}{|c|c|c|c|c|c|c|}
\hline Parameter & AUC & Cut of Point & Sensitivity & Specificity & PPV & NPV \\
\hline Serum Amyloid A & $\mathbf{0 . 9 0 7}$ & $>15.4$ & 77.5 & 95.0 & 96.9 & 67.9 \\
\hline
\end{tabular}

Figure (1): Receiver operating characteristic curve (ROC) for the serum amyloid $A$ as a predictor for patients with placenta accrete and placenta previa 
There was a statistically significant difference between three groups regarding level of serum amyloid A which was high in placenta previa group (Table 5).

Table (5): Level of serum Amyloid A in normal, placenta previa and placenta accreta

\begin{tabular}{|l|c|c|c|c|}
\hline \multirow{2}{*}{ Serum Amyloid A } & Normal group & Placenta previa & Placenta accreta & \multirow{2}{*}{ P-value } \\
\cline { 2 - 4 } & No. = 20 & No. = 20 & No. $=\mathbf{2 0}$ & \\
\hline Mean \pm SD & $11.56 \pm 2.19$ & $20.60 \pm 6.09$ & $19.13 \pm 5.37$ & \multirow{2}{*}{0.000} \\
\hline Range & $8.8-16.2$ & $10.5-30.3$ & $9.2-29.3$ & \\
\hline
\end{tabular}

•: One Way ANOVA test

The best cut off point regarding serum amyloid A between normal placenta patients and placenta previa patients was found > 16.2 with sensitivity of $75.0 \%$, specificity of $100.0 \%$ and area under curve (AUC) of $91.9 \%$. The best cut off point regarding serum amyloid A between normal placenta patients and placenta accrete patients was found > 15.4 with sensitivity of $80.0 \%$, specificity of $95.0 \%$ and area under curve (AUC) of $89.6 \%$ (Figure 2).

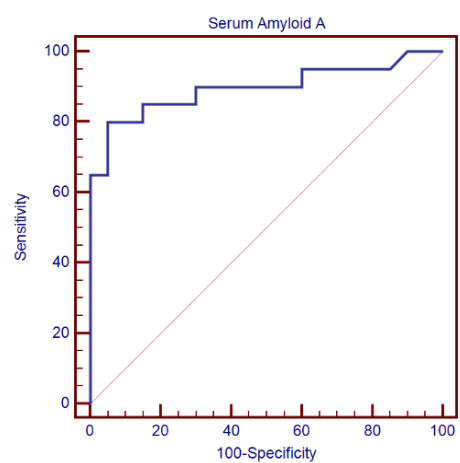

\begin{tabular}{|c|c|c|c|c|c|c|}
\hline Serum Amyloid A & AUC & $\begin{array}{c}\text { Cut of } \\
\text { Point }\end{array}$ & Sensitivity & Specificity & PPV & NPV \\
\hline Normal group Vs previa & $\mathbf{0 . 9 1 9}$ & $>16.2$ & $\mathbf{7 5 . 0}$ & $\mathbf{1 0 0 . 0}$ & $\mathbf{1 0 0 . 0}$ & $\mathbf{8 0 . 0}$ \\
\hline $\begin{array}{c}\text { Normal group Vs } \\
\text { accreta }\end{array}$ & $\mathbf{0 . 8 9 6}$ & $>15.4$ & $\mathbf{8 0 . 0}$ & $\mathbf{9 5 . 0}$ & $\mathbf{9 4 . 1}$ & $\mathbf{8 2 . 6}$ \\
\hline
\end{tabular}

Figure (2): Receiver operating characteristic curve (ROC) for the serum amyloid $A$ as a predictor for patients with placenta accrete and placenta previa from the normal placenta patients

There was no statistically correlation between serum amyloid A and age, BMI,
GA and number of cesarean section (Table 6).

Table (6): Correlation between Serum Amyloid A and Demographic data in (All patients, Placenta previa, and Placenta accrete)

\begin{tabular}{|l|c|c|c|c|c|c|}
\hline \multirow{2}{*}{} & \multicolumn{6}{|c|}{ Serum Amyloid A } \\
\cline { 2 - 7 } & \multicolumn{2}{|c|}{ All patients } & \multicolumn{2}{c|}{ Placenta previa } & \multicolumn{2}{c|}{ Placenta accreta } \\
\cline { 2 - 7 } & r & P-value & r & P-value & r & P-value \\
\hline Age & 0.249 & 0.121 & 0.211 & 0.373 & 0.404 & 0.078 \\
\hline BMI & 0.050 & 0.757 & -0.032 & 0.895 & 0.228 & 0.334 \\
\hline GA & 0.205 & 0.205 & 0.107 & 0.653 & 0.321 & 0.167 \\
\hline Hysterotomy (CS) & 0.188 & 0.246 & 0.190 & 0.423 & 0.252 & 0.284 \\
\hline
\end{tabular}




\section{SERUM AMYLOID A AS A NOVEL MARKER TO MORBIDLADHERENT... 443}

\section{DISCUSSION}

This study aimed to use SAA as a biochemical marker in diagnosis of MAP with ultrasound \& Doppler findings\& if maternal serum serum amyloid A level served as an addition to ultrasonography in the diagnosis of MAP.

The current study is a prospective cohort study, conducted on (60) pregnant women who were divided into three equal groups as follows (20) women with placenta previa, (20) women with placenta accreta or increta and (20) normal pregnant women at a tertiary center: $\mathrm{Al}$ Azhar University Maternity Hospital during the period between February 2019 and October 2019.

As regards SAA assessment as single marker in patients with placenta previa, patients with placenta previa and patients with normal placenta we found that There was a statistically significant difference between three groups regarding level of serum amyloid A which was high in placenta previa group, The best cut off point regarding serum amyloid A to differentiate between normal placenta patients and placenta accreta and previa patients was found $>15.4$ with sensitivity of $77.5 \%$, specificity of $95 \%, \mathrm{PPV}$ 96.9\%,NPV $67.9 \%$ and area under curve (AUC) of $90.7 \%$.

Which indicates that it had significant high diagnostic performance in differentiating placenta previa from normal with no significant difference between previa and accerta group.

Which disagree with the results of Shith et al (2009) who found that 3D power Doppler was the best single way for the diagnosis of placenta accreta, with a sensitivity of $97 \%$ and a specificity of 92\%. 3D power Doppler gave the best PPV (76\%), followed by gray-scale and color Doppler (47\%).3D power Doppler alone yielded the fewest false positive diagnoses, this difference with our study may be due to ultrasound interpreter.

These results were in agreement to the results of other studies as follows:

Cali et al. (2013) enrolled 187 patients with placenta previa and history of uterine surgery and performed transabdominal and transvaginal ultrasound examination for early detection of MAP with 2D grayscale ultrasonography, \&using transabdominal 3D power Doppler.

Ultrasound findings were reviewed against the final diagnosis made during Cesarean section.

In 41 cases, a hysterectomy was performed following confirmation of a lack of placental detachment. In each of the 41 confirmed cases, at least two of the sonographic criteria of invasion were present; with at most one of the criteria present in patients without MAP (morbidly adherent placenta) by 2D grayscale US, 3D power Doppler confirmed the gray-scale and color Doppler data. On the other hand, in the case of placenta previa without accreta, $3 \mathrm{D}$ rendering confirmed that the serosabladder wall interface was not affected by vascularization (Cali et al., 2013).

From my point of view, increase in PPV which represents increase in detection of true cases of MAP, may be the most important of all values in our situation.

This opens the field for the use of multi preoperative modalities in detection of 
MAP, rather than use of either sonographic or biochemical marker alone.

As operative interventions in MAP need multidisplinary team, it seems that accurate preoperative diagnosis of morbidly adherent placenta worthy to have a combination of more than one tool, aiming for proper preoperative preparation regarding transferral to tertiary hospital, preoperative ureteric stents insertion, available blood products, skilled obstetricians in caesarian hysterectomy \&devascularization techniques.

Increase in detection rate of MAP makes preoperative preparations beneficial \&cost effective.

Being cheap, available test, SAA assay when used in combination with 2DUS with 3DPD showed increase in detection rate of MAP

SAA assay alone reliable, ultrasound examination results are good, combination of both is better, but we are searching for the ideal aiming to decrease maternal morbidity \& mortality\& to eliminate the fear associated with preoperative consent taken for hysterectomy in patients with no placental invasion.

\section{CONCLUSION}

Morbidly adherent placenta (MAP) is characterized by failure of the placenta to separate at delivery, with potential for significant perinatal and maternal morbidity and mortality. Antenatal diagnosis of placenta accreta, as it can reduce maternal morbidity by enabling for a scheduled delivery. Ultrasound identifies many, but not all, women with MAP. Detection of level of maternal SAA can be used as an additional tool to detect MAP. This opens the field for the use of multi pre-operative modalities in detection of MAP, rather than use of either sonographic or biochemical marker alone.

\section{REFERENCES}

1. Cali G, Giambanco L, Puccio $G$ and Forlani F (2013): Morbidly adherent placenta: evaluation of ultrasound diagnostic criteria and differentiation of placenta accreta from percreta. Ultrasound in Obstetrics \& Gynecology, 41(4):406-12.

2. Cheung $C$ and Chan B (2012): The sonographic appearance and obstetric management of placenta accreta Int J Womens Health, 4: 587-594.

3. Goh W and Zalud L (2016): Placenta accreta: Diagnosis, management and the molecular biology of the morbidly adherent placenta J Matern Fetal Neonatal Med, 29(11): 1795-1800.

4. Bartels HC, Postle JD, Downey $P$ and Brennan DJ (2018): Placenta Accreta Spectrum: A Review of Pathology, Molecular Biology, and Biomarkers Dis Markers, Dis Markers. 2018 Jul 3; 2018:1507674.

5. Sandri S, Urban Borbely A, Fernandes I, de Oliveira EM and KnebelFH (2014): Serum amyloid $\mathrm{A}$ in the placenta and its role introphoblast invasion. PLoS One, 9: e90881.

6. Shih JC, Jaraquemada JP, Su YN, Shyu MK, Lin CH, Lin SY and Lee CN (2009): Role of three-dimensional power Doppler in the antenatal diagnosis of placenta accreta: comparison with gray-scale and color Doppler techniques. Ultrasound in Obstetrics and Gynecology, 33(2):193-203.

7. Tikkanen M, Paavonen J, Loukovaara M and Stefanovic V (2011): Antenatal lood loss. Acta Obstet Gynecol Scand, 90: 1140-114.

8. Valentini A, Gui B and Ninivaggi V (2017): The morbidly adherent placenta: when and what association of signs can improve MRI diagnosis? Our experience. Diagn Interv Radiol, 23(3): 180-186. 


\section{مصل الاميلويد أ كعلامه في تشخيص المشيمة الملتصقة} خالد زكريا الشيخه، عبدالمنصف عبدالحميد صديق، أحمد عبد الحميد أبو زيلث*، عمرو حسن محمد الشايب

قسمى أمراض النساء والتوليد و الباثولوجيا الإكلينيكة*ث، كلية الطب، جامعة الأزهر

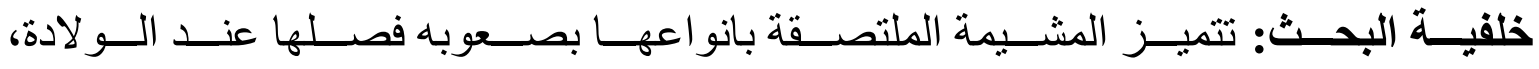

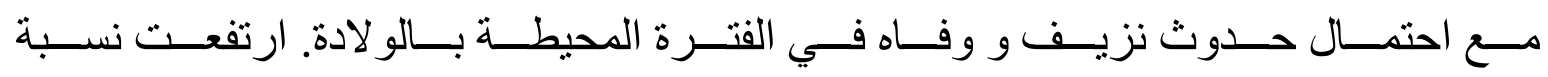

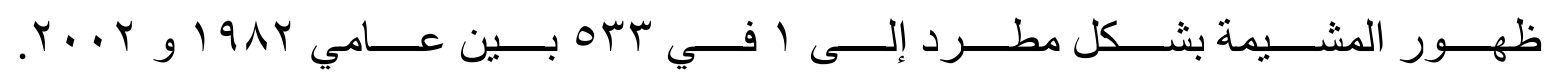

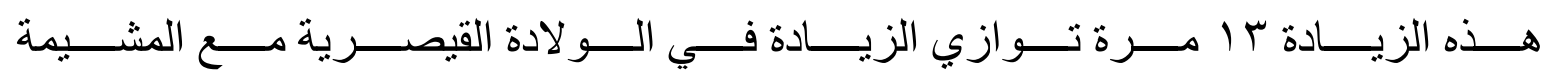

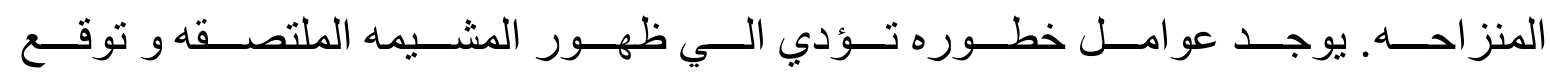

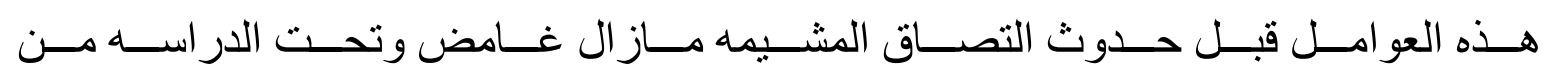

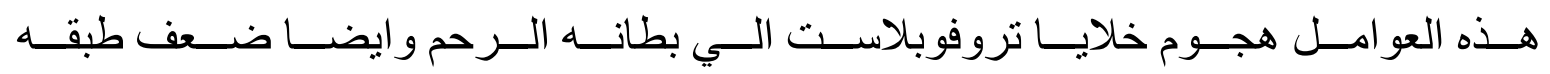

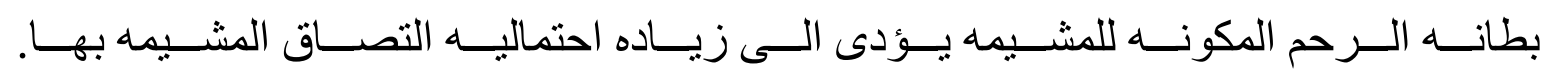

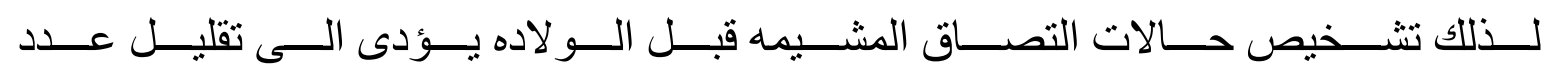

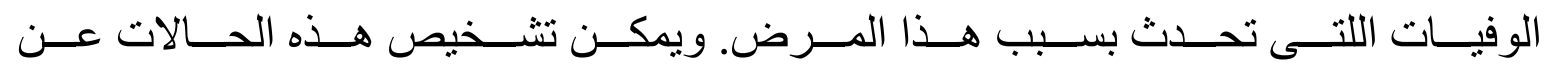

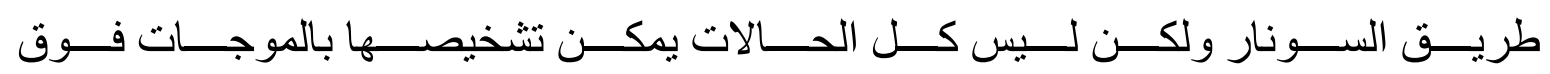

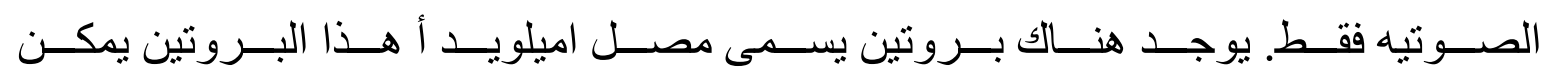

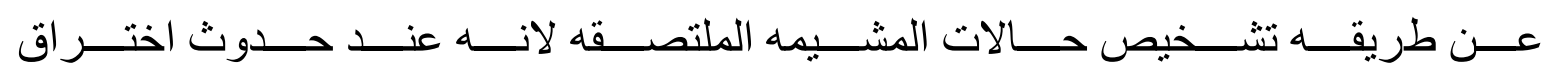

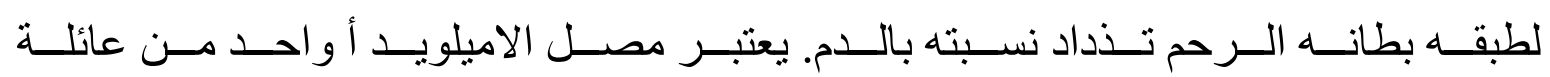

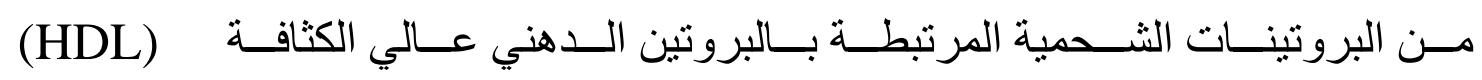
في البلازما ويتم إنتاجه عن عن طريق الكبد.

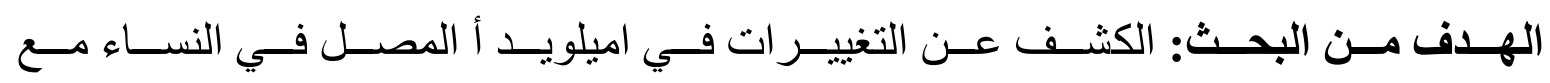

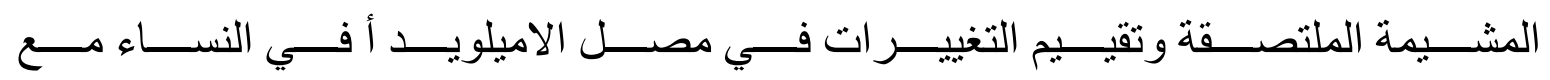

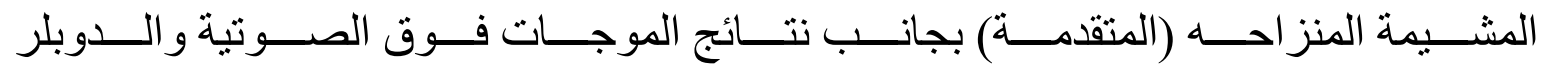
للكثف السابق للو لادة للمشيمة الملتصقة. 


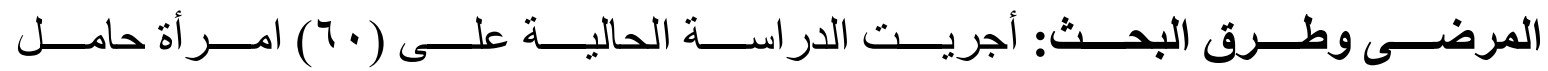

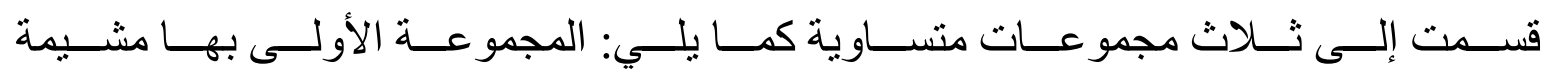

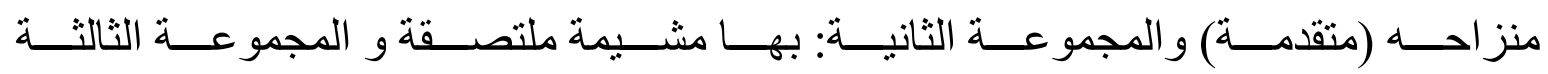
بها مشيمة عادية .

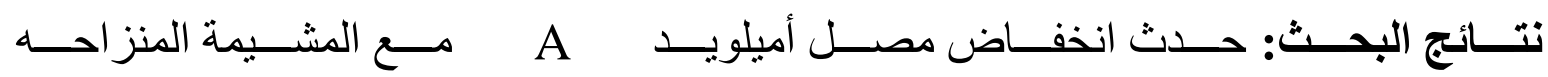

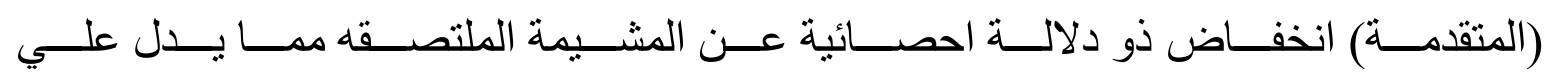

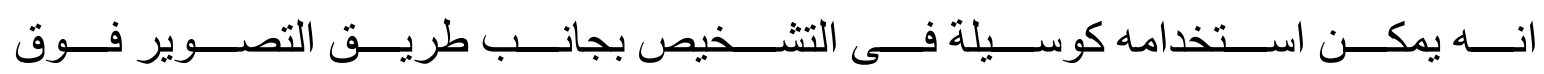
الصوتي.

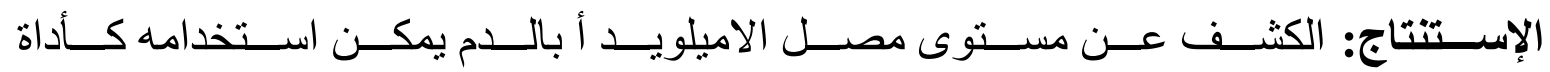
إضافية للكثف عن مرض المثيمه الملتصقه. 